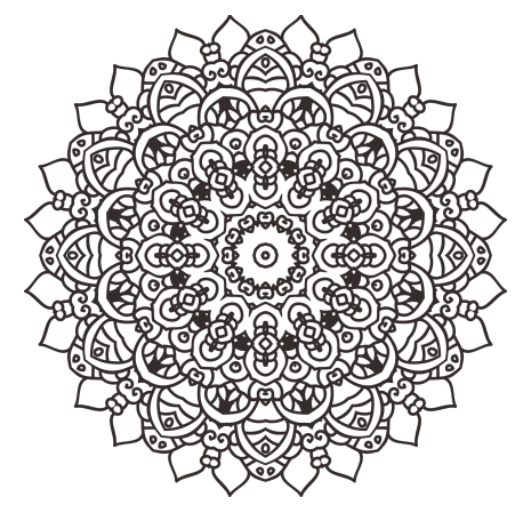

\title{
DIMENSI KONDISIONALITAS DAN FLEKSIBILITAS AL-OUR'AN BAGI IMPLEMENTASI FATWA DSN-MUI TENTANG PRODUK BANK SYARIAH
}

\author{
${ }^{1}$ Ahmad Hasan Ridwan, ${ }^{2}$ Asep Rahmat \\ ${ }^{1}$ Fakultas Syariah dan Hukum UIN Sunan Gunung Djati Bandung \\ ${ }^{2}$ Pascasarjana UIN SUnan Gunung Djati Bandung \\ E-mail : ahmadhasanridwan@uinsgd.ac.id, rasyd_asep@yahoo.com
}

\begin{abstract}
This study discusses the dimensions of the conditionality of the Koran, the flexibility of the Koran, and the implementation of the National Sharia Council of the Indonesian Ulema Council Center for the dimension of conditionality and the dimension of the flexibility of the Koran regarding sharia bank products in Indonesia. With a qualitative approach and content analysis method, it is found that the conditionality of the Koran means the conditioning demanded by 'illat al-hukm (legal motives) within the framework of tathbiq al-hukm (application of the law). The dimension of the versatility of the Koran shows that the existence of the Koran is always flexible in responding to demands the size of the place and time that surrounds it without ignoring the objectives of the shari'a. Indonesia has an Indonesian Ulama Council (MUI) which appoints its National Sharia Council (DSN) -MUI work unit as a fatwa authority institution that enters into the sharia application legislation regulation legislation practiced by the banking world in Indonesia. Islamic banks after obtaining legislation from Bank Indonesia and issued regulations by the Financial Services Authority (OJK). The presence of the DSN Fatwa institution is evidence of the dimensions of conditionality and flexibility of the verses of the Koran in the field of Islamic economics.
\end{abstract}

Keywords: fatwa DSN, conditionality, flexibility 
Abstrak: Penelitian ini membahas tentang dimensi kondisionalitas Al-Qur'an, fleksibilitas Al-Qur'an, dan implementasi Dewan Syariah Nasional Majelis Ulama Indnonesia Pusat dimensi kondisionalitas dan dimensi fleksibilitas Al-Qur'an tentang produk bank syari'ah di Indonesia. Dengan pendekatan kualitatif dan metode analisis isi (content analysis) diperoleh bahwa kondisionalitas Al-Qur'an bermakna pengkondisian yang dituntut oleh 'illat al-hukm (motif hukum) dalam kerangka tathbiq al-hukm (pengaplikasian hukum). Dimensi fleksibilitas Al-Qur'an menunjukkan bahwa eksistensi Al-Qur'an senantiasa luwes merespon tuntutan, seukuran dengan tempat dan waktu yang melingkupinya tanpa mengabaikan tujuan syari'ah. Indonesia memiliki lembaga Majelis Ulama Indonesia (MUI) yang menunjuk unit kerjanya Dewan Syariah Nasioanl (DSN) MUI sebagai lembaga otoritas fatwa yang masuk ke dalam wilayah regulasi legislasi aplikasi akad syariah yang dipraktikkan oleh dunia perbankan di Indonesia. Bank syariah setelah mendapatkan legislasi dari Bank Indonesia dan diterbitkan peraturan oleh Otoritas jasa Keuangan (OJK). Kehadiran institusi Fatwa DSN merupakan bukti implikasi dimensi kondisionalitas dan fleksibilitas ayat-ayat Al-Qur'an dalam bidang ekonomi syariah.

Kata kunci: fatwa DSN, kondisionalitas, fleksibilitas 


\section{Pendahuluan}

Al-Qur'an secara konsisten diyakini sepenuh hati sebagai pedoman hidup, sebagai landasan utama (al-mashdar) yang solutif. Keabadian kebenaran Al-Qur'an tak lekang oleh zaman. la kitab yang menghimpun (jâmi), diturunkan sebagai pemberi penjelasan eksplisit (tibyan) bagi segala sesuatu dan sebagai petunjuk serta rahmat bagi kaum yang mengimani ${ }^{1}$. Allah 'Azza wa Jalla di dalam O.S. Al-Isra: 82 berfirman: "Dan kami turunkan dari Al-Our'an (sesuatu) yang menjadi penawar dan rahmat bagi orang-orang yang beriman, sedangkan bagi orang yang zhalim (Al-Qur'an itu) hanya akan menambah kerugian."

Fuqaha sepakat bahwa Al-Qur'an sebagai sumber hukum Islam dan membagi subtansinya ke dalam dua kategori. Pertama, al-Figh al-Akbaryang berisi tentang ketuhanan, kenabian dan imamah; kedua, al-Fiqh (al-Figh al-Ashghar) mengenai tuntunan dalam masalah ibadah dan muamalah. Hukum Islam (Islamic law) atau al-Figh merupakan salah satu unsur utama ajaran Islam. Berbeda dengan dua unsur utama ajaran Islam yang lain yakni akidah dan akhlak, fikih menempati posisi paling sentral karena ia menandai keislaman seseorang secara formal. Ini dikarenakan fikih berisi ajaran Islam yang bersifat praktisimplementatif dan bercorak lahiriah, yang berupa aturan-aturan hidup praktis yang meliputi aspek ritual (ibadah) dan aspek sosial (muamalah).

Al-Fiqh merupakan hasil interpretasi para ulama terhadap teks al-Qur'an dan alSunnah, oleh karenanya sifatnya dzanniyah (relatif) dan sangat memungkinkan terjadi perbedaan pendapat ulama yang satu dengan yang lainnya. Perbedaan tersebut banyak disebabkan oleh berbagai faktor di antaranya faktor paradigma keilmuan mujtahid, tempat, waktu ataupun keadaan sosial masyarakat. Relevansi produk ijtihad dengan penyelesaian masalah haruslah sesuai dengan konteks zamannya. Hal ini menunjukkan fleksibelitas yang meniscayakan kedinamisan tersebut pada gilirannya memungkinkan hukum Islam memberikan jalan keluar bagi setiap persoalan yang muncul dari waktu ke waktu, serta mampu menciptakan masyarakat yang lebih baik.

Kedinamisan atau kelenturan hukumnya bersumber kepada ayat-ayat Al-Qur'an yang memiliki karakter kondisionalitas dan fleksibel. Kitab yang menghimpun (jami), diturunkan sebagai pemberi penjelasan secara eksplisit (tibyan) bagi segala sesuatu dan sebagai petunjuk serta rahmat bagi kaum yang mengimani ${ }^{2}$. Fleksibelitas yang meniscayakan kedinamisan tersebut pada gilirannya memungkinkan hukum Islam memberikan jalan keluar bagi setiap persoalan yang muncul dari waktu kewaktu, serta menjadikan hukum Islam dapat merespons dinamika kehidupan yang terus berkembang sebagaimana pesatnya perkembangan bidang muamalah. Pertanyaan-pertanyaan yang muncul yang mengantarkan seorang mufassir dapat menginterpretasikan ayat-ayat hukum dalam Al-Qur'an sesuai

\footnotetext{
${ }^{1}$ Muhamad Ali Al-Shabuni, Al-Tibyan Fi 'Ulum Al-Quran, (Dar Al-Mawahib Al-Islamiyat, 2016), hlm.
} 75 .

\footnotetext{
${ }^{2}$ Muhamad Ali Al-Shabuni, Al-Tibyan, hlm. 75.
} 
dengan kompetensi dan kondisi mufassir. Hasil ljtihad yang dihasilkan secara individual (ijtihad fardi) ataupun secara komunal (ijtihad jama'i) memiliki perbedaan-perbedaan.

Berdasarkan penjelasan di atas, maka tulisan ini akan membahas Dimensi Kondisionalitas dan Fleksibilitas Ajaran Al-Qur'an dan implementasi Fatwa Dewan Syariah Nasional MUI Pusat tentang produk bank syari'ah.

\section{Metode Penelitian}

Penelitian ini menggunakan jenis penelitian kepustakaan. Di mana sumber atau referensi yang diperoleh melalui sumber-sumber dan referensi yang ada berhubungan dengan pembahasan ${ }^{3}$. Karena itu, penelitian tentang Dimensi Kondisionalitas dan Fleksibilitas Ajaran Al-Qur'an dan implementasi Fatwa Dewan Syariah Nasional MUI Pusat tentang produk bank syari'ah ini menggunakan metode penelaahan data dan analisis yang berkembang. Pendekatan kualitatif normatif merupakan salah satu metode pendekatan yang digunakan dalam penelitian ini, sehingga bahan pustaka yang ada digunakan sebagai referensi penelitian ${ }^{4}$.

Selain itu, penulis menggunakan teknik pengumpulan data ${ }^{5}$, yaitu dengan melakukan pendekatan terhadap berbagai literatur yang terpercaya serta dapat dibuktikan keabsahannya dengan cara mengkaji berbagai sumber referensi terpercaya yang kemudian dianalisi secara mendalam. Selanjutnya, penelitian ini menggunakan teknis analisis deskriptif, di mana analisa pembahasan menggunakan metode pemaparan sumber-sumber yang telah terkumpul untuk disusun secara sistematis ${ }^{6}$. Untuk melengkapi pembahasan, dikumpulkan juga beberapa dokumen hasil informasi dari berbagai tulisan.

\section{Hasil dan Pembahasan}

\section{Hakikat Dimensi Kondisionalitas Al-Qur'an}

Dimensi adalah ukuran yang meliputi panjang, lebar, tinggi, luas, dan sebagainya. ${ }^{7}$ Dimesi juga bermakna salah satu aspek yang meliputi atribut, elemen, item, fenomena, situasi dan faktor yang membentuk suatu entitas, yakni sesuatu yang memiliki keberadaan yang unik dan berbeda. Selain untuk menunjukkan ukuran sesuatu, istilah dimensi juga bisa digunakan untuk menunjukkan sisi, bagian, aspek, atau sudut pandang sesuatu. Misalnya istilah dimensi hukum untuk menunjukkan segi hukum yang menjadi fokus peninjauan. Pengertian dimensi dalam penelitian adalah indikator ataupun variabel yang dikaji di dalam suatu penelitian yang bertujuan untuk memberikan suatu arahan mengenai pengukurannya. ${ }^{8}$

\footnotetext{
${ }^{3}$ Moh. Nazir, Metode Penelitian (Bandung: Ghalia Indonesia, 2003), hlm. 193.

${ }^{4}$ Suerjono Sukanto dan Sri Mamudji, Penelitian Hukum Normatif Suatu Tinjauan Singkat, Cet. 11 (Jakarta: PT. Raja Grafindo Persada, 2009), hlm. 13-14.

${ }^{5}$ Sugiyono, Metode Penelitian Kuantitatif, Kualitatif Dan R\&D (Bandung: Alfabeta, 2013), hlm. 224.

${ }^{6}$ Jalaludin Rahmat, Metodologi Hukum (Jakarta: Fajar Agung, 1997), hlm. 134.

${ }^{7}$ https://kkbi.web.id/dimensi.html, diakses pada tanggal 11 Mei 2020

${ }^{8}$ www.pengertianmenurutparaahli.net, diakses pada tanggal 11 Mei 2020
} 
Kondisionalitas Al-Qur'an bermakna pengkondisian yang dituntut oleh 'illat al-hukum (motif hukum) dalam kerangka tathbiq al-hukm (pengaplikasian hukum) yang dikehendaki oleh faktor keadaan, waktu, dan tempat sehingga hukum berubah dari 'azimah (asalnya) jika 'illatnya manshush 'alaih menjadi rukhshah, jika 'illatnya ghair manshus terhadap kasus baru bisa diterapkan qiyas (analogi), atau bagaimana mengaplikasikan dalil-dalil umum yang diteliti bahwa masalah yang dihadapi bagian dari particular keumumannya. Banyak ayat yang "membuka luang" praktik penerapan hukum Al-Qur'an itu mudah. Di dalam Q.S. AlTaghabun: 16: "Maka bertakwalah kamu kepada Allah seukuran kemampuanmu ..."9

Al-Zuhaili memahami ayat tersebut "hendaknya mengerahkan di dalam bertakwa kepada-Nya secara kesungguhan dan kemampuan kalian. ${ }^{10}$ Utsaimin $^{11}$ memberi paparan atas penafsiran ayat tersebut, manusia jika tidak mampu melaksanakan perintah Allah menurut cara yang sempurna, maka hendaknya ia melaksanaknnya seukuran kemampuannya. Praktik ini tercermin pada kegiatan shalat sebagaimana perintah Nabi kepada Imran bin Hushain: "Shalatlah Engkau dalam kondisi berdiri, jika tidak mampu hendaknya shalat dalam kondisi duduk, jika tidak mampu (duduk) hendaknya shalat dalam kondisi berbaring". Adapun di dalam urusan shaum apabila seseorang tidak mampu melaksanakan shaum Ramadhan di dalam Q.S. Al-Baqarah: 182, "Maka barangsiapa di antara kamu yang sakit atau dalam perjalanan hendaknya diganti pada hari-hari yang lain ..."12. Apalagi di dalam urusan haji yang melibatkan pengerahan harta dalam menyampaikan kepada pelaksanaan kewajiban, di dalam Q.S. Al- Imran: 97: "...dan di antara kewajiban manusia terhadap Allah adalah melaksanakan haji ke Baitullah yaitu bagi orang-orang yang mampu mengadakan perjalanan kesana..." ${ }^{13}$

Dari pemahaman ayat-ayat tersebut di atas, ulama menarik qa'idah fiqhiyah dalam upaya pengkondisian praktik penerapan Al-Qur'an di antaranya:

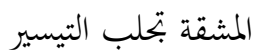

"Kesulitan itu mendatangkan kemudahan."14

Semua rukhshah (dispensasi) di dalam praktik peribadatan pada esensinya untuk meraih semangat syariat dalam bingkai kondisionalitas setaraf al-hajiyyat (kebutuhan) supaya level al-dharuruyat (yang mesti) tetap terlaksanakan. Dimensi kondisionalitas ini asas legalitasnya disebutkan di dalam Q.S. al-Hajj:78:

\footnotetext{
${ }^{9}$ Anonimous, Al-Quran Hafalan Mudah, Banung : Cordoba, 2018, hlm.557

${ }^{10}$ Wahbah bin Mushtafa Al-Zuhaili, Tafsir Al-Munir, Dar Al-Fikr, Damaskus: 1418 H, Jld.XXVIII, hlm. 252.

${ }^{11}$ Muhamad bin Shalih Al-'Utsaimin, Syarh Riyadh Al-Shalihin, Dar Ibn 'Ashashat, Beirut: 2006, Jld. I, hlm. 224.

${ }^{12}$ Anonimous, Al-Quran Hafalan Mudah, Cordoba, Bandung: 2018, hlm. 28.

${ }^{13}$ Anonimous, Al-Quran, hlm. 62.

${ }^{14}$ Abdul Hamid Hakim, Mabadi'u Awaliyat, Maktabat Al-Sa'adiyat Putra, Jakarta: 2007, hlm. 30.
} 


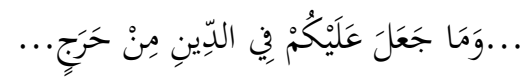

".....Dan tidaklah Dia menjadikan bagi kalian di dalam urusan agama suatu kesulitan ....."15

Al-Qasimi ${ }^{16}$ menafsirkan ayat tersebut dengan:

ليدل على أن المطلوب القيام بمواجبه وشرائطه على وجه التمام والكمال بقدر الطاقة.

"Supaya menunjukkan bahwa berbagai pewajiban dan syarat-syaratnya menurut cara yang lengkap dan sempurna seukuran kemampuan."

Kemudian ulama menarik Qaidah fiqhiyah yang menjelaskan:

$$
\text { الأمور إذا اتسعت ضاقت وإذا ضاقت اتسعت }
$$

"Berbagai urusan itu apabila ia lapang, maka menjadi sempit dan apabila ia sempit maka menjadi lapang".

Adapun bagi persoalan baru yang tidak pernah ada pada masa Rasulullah SAW. hidup, ulama yang konsen mempraktikkan mertode qiyas (analogi) mencari kesamaan 'illat hukumnya sesuai dengan hukum ashalnya. Praktik penerapan analogi sebagai landasan ijtihady disandarkan pada dalil Al-Qur'an Q.S. Al-Hasyr: 2: "...Maka ambillah pelajaran wahai kaum yang berpandangan....." ${ }^{17}$

Al-Lusi ${ }^{18}$ memberikan penafsiran terhadap ayat tersebut:

$$
\text { واشتهر الاستدلال بالآية على مشروعية العمل بالقياس الشرعي، قالوا: إنه تعالى أمر فيها بالاعتبار وهو }
$$

"dipopulerkan pengambilan dalil dengan ayat tersebut pensyariatan praktik qiyas (analogi) secara syar'i. Mereka berpendapat: Sesungguhnya Allah Ta'ala memerintahkan di dalam kandungan ayat tersebut agar mengambil i'tibar (pelajaran), yaitu memindahkan dan mengalihkan dari sesuatu kepada selainnya, yang demikian itu menentukan qiyas (analogi) ketika pemindahan hukum dari ashal (pokok) kepada al-far'u (cabang).

Kemudian di dalam Q.S. Al-Nahl:9o "Sesungguhnya Allah memerintahkan kalian beraku adil dan berbuat kebajikan...."19 Konsep "adil" itu adalah mempersamakan dan

\footnotetext{
${ }^{15}$ Anonimous, Al-Quran, hlm. 108

${ }^{16}$ Muhamad Jamal Al-Din bin Sa'id bin Qasim Al-Halaq Al-Qasimi, Mahasin Al-Ta'wil, dar Al-Kutub Al-'llmiyat, Beirut: 1418 H, jld. VII, hlm. 278.

${ }^{17}$ Anonimous, Al-Quran Hafalan Mudah, Cordoba, Bandung: 2018, 545

${ }^{18}$ Syihab Al-Din Mahmud bin Abdillah Al-Husaini Al-Alusi, Ruh Al-Ma'ani, Dar Al-Kutub Al-'llmiyat, BeirutL 1415 H, jld.XIV, hlm. 235.
} 
qiyas berarti mempersamakan antara dua urusan yang sebanding di dalam hukumnya, maka pemahamannya diambil berdasarkan keumuman ayat. ${ }^{20}$ Di kalangan Mayoritas 'ulama qiyâs termasuk di antara mashadir al-ahkam (sumber-sumber hukum) yang disepakati setelah Al-Qur'an, Al-Sunnah, dan ijma' untuk dipakai sebagai hujjah (argumentasi). Maksudnya satu sumber di antara sumber-sumber legislasi di dalam hukum-hukum syariat dan 'amaliyat. ${ }^{21}$

Umum Al-Dalil penerapannya (tathbiq) dipraktikkan oleh ulama dalam pengkondisian Al-Qur'an. Contoh di antaranya ditegaskan O.S. Al-Baqarah: 29: "Dialah (Allah) yang telah menciptakan bagi kalian apa-apa yang ada di bumi ini semuanya ......"22

Al-Thanthawi ${ }^{23}$ menafsirkan ayat tersebut:

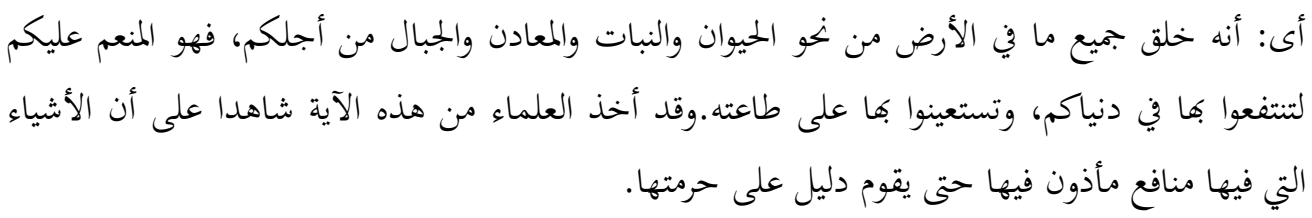

"Maksudnya, sesungguhnya Dia telah menciptakan semua yang ada di bumi contoh hewan, tumbuhan, barang tambang bagi kalian. Dia pemberi nikmat atas kalian agar mengambil manfaat bagi urusan dunia dan memohon sarana pertolongan dengannya untuk mentaati-Nya. Sungguh ulama telah mengambil dari ayat ini saksi bahwa segala sesutu yang terkandung manfaat diperkenankan sehingga ada dalil pengharamannya."

Imam Shubhi Shalih ${ }^{24}$ mendefinisikan, bahwa yang dimaksud dengan 'am AlQur'an adalah term yang didapat padanya dalil dalam pokok penetapan. Secara bahasa menghabiskan semua satuan-satuannya yang membenarkan maknanya tanpa ada pembatasan. Al-Qur'an yang diturunkan dengan bahasa Arab mengungkapkan keumuman dengan lafazh-lafazh yang orang Arab menetapkannya untuk memaidahkan al-syumul (mencakup) dan al-istighraq (menghabiskan) makna.

Menurut pandangan mayoritas Ahli Ushul sesungguhnya yang umum tetap atas keumumannya menunjukkan semua satuan-satuannya, hukumnya menetapkan bagi semua yang diambil oleh lafazh-lafazhnya selama tidak ada dalil yang mengkhususkannya. Mereka mengambil dalil dengan argumen sebagai berikut:

\footnotetext{
${ }^{19}$ Anonimous, Al-Quran Hafalan Mudah, Cordoba, Bandung: 2018, 277

${ }^{20}$ Abd Al-Hamid Al-Hakim, Al-Sullam, Al-Sa'adiyat, Putra, Jakarta: 2007, hlm. 43.

${ }^{21}$ Wahbat Al-Zuhaili, Ushul Al-Fiqh Al-Islami, Dar Al-Fikr, Damaskus: 2006, jld. I, hlm. 577.

${ }^{22}$ Anonimous, Al-Quran Hafalan Mudah, Cordoba, Bandung: 2018, hlm. 5.

${ }^{23}$ Muhamad Sayyid Thanthawi, Al-Tafsir Al-Wasith Li Al-Quran Al-Karim, Dar Nahdhat, Kairo: 1997,

${ }^{24}$ Shubhi Al-Shalih, Mabahits Fi 'Ulum Al-Quran, Dar Al-'1/m Lil Malayin, Beirut: 1988, hlm. 308.
} jld . I, hlm. 28. 
Pertama: Al-Qur'an, di dalam Q.S. Al-An'am: 91 :

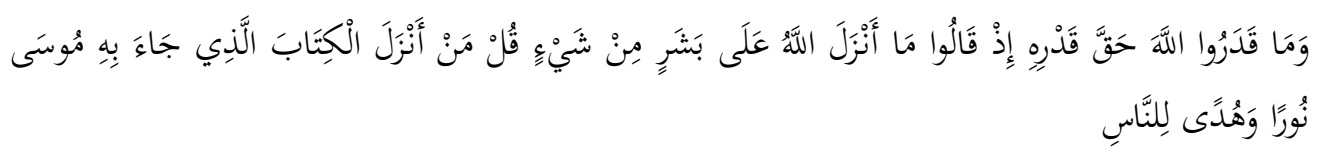

"Mereka tidak mengagungkan Allah sebagaimana mestinya ketika mereka berkata: "Allah SWT tidak menurunkan sesuatupun kepada manusia." Katakanlah (Muhamad): Siapakah yang menurunkan kitab (Taurat) yang dibawa Musa sebagai cahaya dan petunjuk bagi manusia, ..."25

Kalimat "basyar", "manusia" dan kalimat "syai'un", "sesuatu" menunjukkan keumuman dan pencakupan yang mengandung dalil penolakan mereka diturunkan kitab atas Musa A.S.

Kedua, Segera dapat diserap pemikiran: sesungguhnya yang umum dapat segera diserap pemikiran bentuk keumumannya dan menyegerakan dalil penetapannya secara hakiki. Umpama ucapan: "Setiap orang yang masuk rumahku niscaya ia akan diberi satu dirham." Tentu tidak akan dilaksanakan urusan itu kecuali memberikannya kepada setiap orang yang masuk.

Ketiga, konsensus para sahabat dan ahli bahasa mempraktikkan lafazh-lafazh AlQur'an dan Al-Sunnah berdasarkankeumumannya sehingga ada dalil atas pengkhususannya. $^{26}$

$$
\text { العام يبقى على عمومه مالم يقم عليه دليل التخصيص }
$$

Teristimewa dalam lapangan mu'amalah madaniyah, dituntut dinamika yang sangat cepat oleh hajat manusia, penggunaan umum Al-Qur'an sesuatu yang tidak terelakan.

Dari keumuman dalil-dalil bermu'amalah itu ulama menarik qaidah fiqhiyah:

$$
\text { الأصل في الأشياء الإباحة حتى يدل الدليل على التحريم }
$$

"Pokok di dalam segala sesuatu itu boleh sehingga dalil menunjukkan pengharamannya."

Sesungguhnya Allah SWT. telah membolehkan beragam perkara yang sangat banyak dan mengharamkan sebagian perkara-perkara, ini merupakan konsensus ulama. Adapun yang didiamkan pembuat syariat, sedangkan tidak datang nash pembolehannya dan begitu juga pengharamannya, dalam pandangan mayoritas 'ulama berarti halal. Argumen ini dikuatkan dengan sabda Nabi SAW:

\footnotetext{
${ }^{25}$ Anonimous, Al-Quran Hafalan Mudah, Cordoba, Bandung: 2018, hlm. 139.

${ }^{26}$ Wahbat Al-Zuhaili, Ushul Al-Fiqh Al-Islami, Dar Al-Fikr, Damaskus: 2006, jld. II, hlm. 243.
} 
ما أحل الله فهو حلال، وما حرم فهو حرام، وما سكت عنه فهو عفو، فاقبلوا من الله عافيته، فإن الله لم

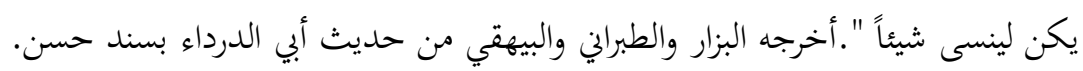

"Sesuatu yang Allah halalkan berarti halal dan sesuatu yang Dia haramkan berarti haram, adapun sesuatu yang Dia diamkan maka berarti dimaafkan, terimalah dari Allah maaf-Nya, karena sesungguhnya Allah tidak ada melupakan sesuatu pun." (Al-Bazzar, Al-Thabarani dan Al-Baihaqi telah meriwayatkannya melalui hadits Abu Darda' dengan sanad hasan). ${ }^{27}$

\section{Hakikat Dimensi Fleksibilitas Al-Qur'an}

Fleksibilitas berarti kelenturan atau penyesuaian diri secara mudah dan cepat; keluwesan; ketidakcanggungan. ${ }^{28}$ Dimensi fleksibilitas Al-Qur'an berarti suatu aspek AlQur'an senantiasa luwes merespon tuntutan seukuran dengan tempat dan waktu yang melingkupinya tanpa mengabaikan tujuan syari'ah. Dari definisi yang penulis sampaikan bukan berarti pada tathbiqnya memudahkan ditarik pada suatu konteks sesuai selera ahl al-ahwa wa al-bida' karena yang demikian mengakibatkan selentur apapun sesuatu yang bersifat fleksibel jika dihabiskan "daya pegas"nya niscaya akan putus. Karena itu, AlQur'an bertutur di dalam Q.S. Al-Nisa:13: "itulah batas-batas Allah..." ${ }^{29}$

Rasyidh Ridha ${ }^{30}$ ketika mengomentari ayat tersebut mengutarakan pendapat gurunya, Syaikh Muhamad Abduh, sebagai berikut:

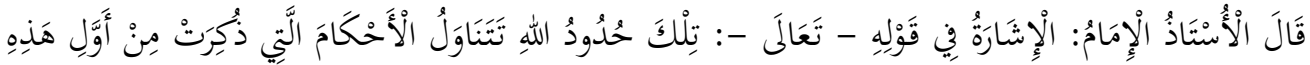

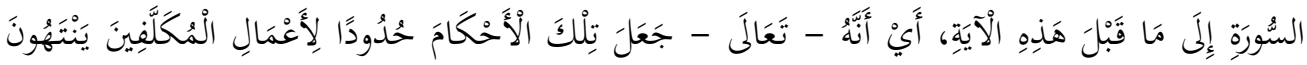

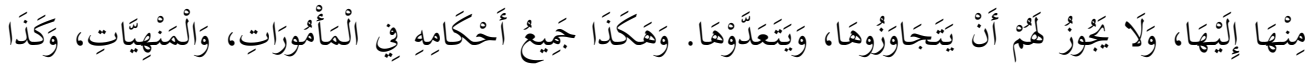

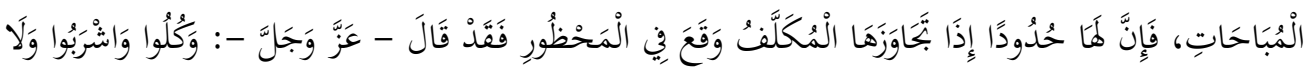

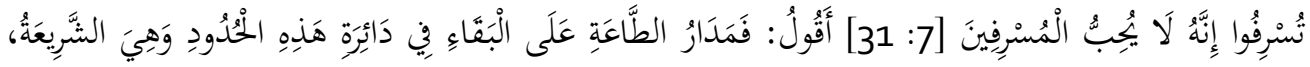

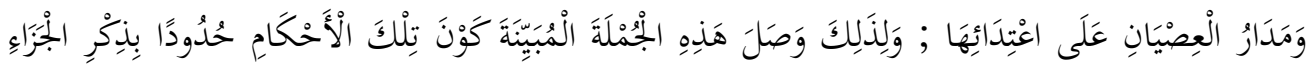

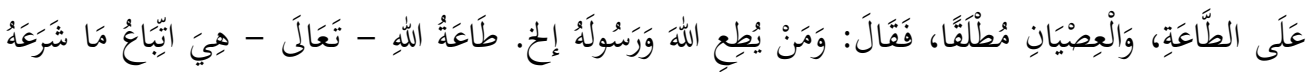

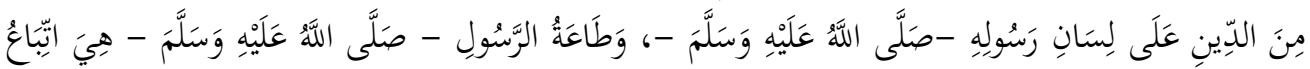

\footnotetext{
${ }^{27}$ Lihat: Muhamad Mushthafa Al-Zuhaili, Al-Oawa'id Al-Fiqhiyyat Wa Tathbiqatuha Fi Al-Madzahib Al-
} Arba'at, Dar Al-Fikr, Damaskus: 2006, jld.l, hlm. 190.

${ }^{28}$ https://kbbi.web.id/fleksibilitas.html, diakses tanggal 18 Mei 2020

${ }^{29}$ Anonimous, Al-Quran Hafalan Mudah, Cordoba, Bandung: 2018, hlm. 79

${ }^{30}$ Muhamad Rasyid bin Ali Ridha bin MUhamad Syams Al-Din bin Muhamad Baha'u Al-Din Ali Khalifat Al-Oalmuni Al-Husaini, Tafsir Al-Manar, Al-Hai'at Al-Mishriyat Al-'Amat Lil Kltab, 1990, jld. IV, hlm. 350. 


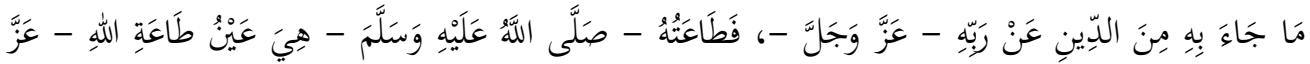

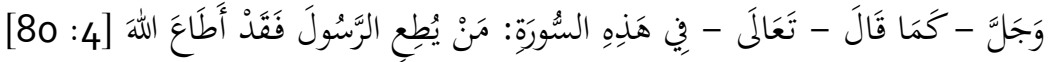

Telah berkata Al-Ustadz Al-Imam: Suatu isyarat di dalam firman-Nya: "Tilka hududullah", "Itulah batas-batas ( hukum ) Allah." Mencakup hukum-hukum yang telah disebutkan mulai surat ini sampai kepada sebelum ayat ini, maksudnya sesungguhnya Allah Ta'ala menjadikan hukum-hukum-Nya itu batasa-batas bagi pengamalan mukallaf (orang yang cakap hukum) yang disampaikan kepada mereka, tidak boleh bagi mereka melewatinya dan melewati batasnya. Yang demikian juga semua hukum-hukum di dalam yang diperintahkan dan yang dilarang serta yangdiperbolehkan, karena sesungguhnya baginya mempunyai batas-batas jika mukallaf melewati batasnya niscaya terjerumus ke dalam yang dilarang. Sungguh Allah 'Azza wa Jalla telah berfirman:

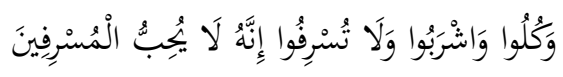

"Makan dan minumlah kalian, tetapi jangan berlebih-lebihan, sesungguhnya Dia tidak menyukai orang yang berlebih-lebihan." (0.S.7:31).

Poros ketaatan itu terus-menerus (konsisten) di dalam pusaran batas-batas ini, yaitu syariat, sebaliknya poros kedurhakaan konsisten di dalam pusaran melewati batas-batas syariat; karena itu Dia menyampaikan susunan kalimat yang dijelaskan keadaan hukum-hukum itu suatu batas-batas dengan menerangkan balasan atas suatu ketaatan dan kedurhakaan secara mutlak, seraya berfirman: "Barangsiapa yang mentaati Allah..." yaitu mengikuti sesuatu yang disyariatkan dari agama ini melalui lisan Rasul-Nya SAW., dan mentaati Rasul-Nya SAW. yaitu mengikuti sesuatu yang dibawa dari agama ini dari Tuhannya 'Azza wa Jalla, berarti dengan mentaati Rasulnya SAW. merupakan ketaatan kepada Allah 'Azza wa Jalla, Q.S. Al-Nisa: 80 :

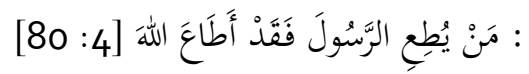

"Barangsiapa mentaati Rasul maka sungguh ia telah mentaati Allah."

Mungkin maksud fleksibel di sini bagi penerapan nash-nash umum yang tidak ditemukan pengkhususannya, sehingga pelaksanaanya sejauh yang dicakup oleh keumuman lafazhnya, sesuai qaidah fiqhiyah:

$$
\text { العام يبقى على عمومه مالم يقم عليه دليل التخصيص }
$$

"Yang umum ditetapkan keumumannya selama tidak berdiri dalil pengkhususannya."

Atau mungkin bagi penerapan ayat-ayat yang zhaniy al-dilalah pada lafazhnya sehngga menjadi lapangan ijtihad mengeluarkan hukum dari dalil-dalil yang terperinci agar mendapatkan istinbath (sari pati) hukum. Atau mungkin bagi kasus-kasus baru yang 
diperlukan analogi sebagai dasar metodologi solusinya sehingga sebanyak mungkin dapat menggali spirit (ruh) syariat. Kontekstual nilai-nilai dasar Al-Qur'an senantiasa dapat membumi seiring dengan perkembangan zaman dan di tempat manapun, tanpa harus merombak dasar-dasar yang qath'iy.

\section{Fatwa DSN MUI Pusat Tentang Produk Bank Syariah}

Di antara kontribusi pemerintah Orde Baru bagi Umat Islam Indonesia adalah berdirinya Bank Muamalat pada tahun 1991 sebagai bank syariah pertama yang dipelopori oleh Majelis Ulama Indonesia (MUI), Cendikiawan Muslim Indonesia (ICMI), pengusaha Muslim, dan pemerintahan Orde Baru pada waktu itu. Sedangkan keberadaan perundang-undangnnya baru lahir tujuh tahun kemudian yaitu Undang-undang Nomor 10 Tahun 1998 tentang Perbankan. Perkembangan bank syariah di Indonesia mencuat setelah terjadi krisis ekonomi dan moneter tahun 1998. Pada waktu itu, ketika dunia perbankan tengah mengalami masa "collapse" karena beban kewajiban bunga yang harus dibayar kepada pihak ketiga sangat tinggi sebagai konsekuensi dari gencar punding agar on standing stabil ternyata tidak terpenuhi, ternyata lain halnya dengan bank syariah. Sistem bagi hasil yang diterapkan bank syariah telah membuat usaha jasa keuangan varian ini mendulang untung yang terbebas dari negative spread. ${ }^{31}$

MUI untuk selanjutnya, sebagai lembaga otoritas fatwa representative perwakilan seluruh ormas Islam di Indonesia, membuat suatu badan khusus yang di sebut dengan DSN (Dewan Syariah Nasional) MUI Pusat untuk mewadahi antusiasme umat Islam di dalam berekonomi syariah di negeri ini agar senantasa sesuai dengan Al-Qur'an dan Al-Sunnah dalam konteks penerapannya bersinergi dengan pemerintah Indonesia. DSN MUI Pusat ini merupakan unit kerja semacam komisi fatwa di MUI Pusat yang menyampaikan fatwa-fatwa bagi Lembaga Keuangan Syariah (LKS) sebagai regulasi yang harus ditaati oleh semua bank syariah setelah mendapatkan legislasi dari Bank Indonesia dan diterbitkan peraturan oleh Otoritas jasa Keuangan (OJK).

Sebenarnya DSN lah yang menjadi ujung tombak bagaimana suatu produk Lembaga Keuangan Syariah, secara khusus bank syariah dilahirkan. Karena secara kelembagaan perbankan tidak pernah ada di zaman Rasulullah SAW. tentu saja ditilik dari posisinya termasuk kategori figh kontemporer yang diproduk dari ijtihad jama'i dalam hal ini DSN-MUI Pusat. Pada akhirnya produk ijtihadi dari produk akad-akad bank syariah ini menjadi fatwa yang wajib dilaksanakan oleh setiap bank syariah, malah dalam aplikasinya mendapatkan pengawasan yang ketat di setiap bank di bawah lembaga yang mendapatkan rekomendasi dari DSN-MUI Pusat sendiri yaitu Dewan Pengawas Syariah (DPS). tabungan.

${ }^{31}$ Negative spread adalah tingkat suku bunga pinjaman lebih rendah daripada tingkat suku bunga 
Telah banyak fatwa DSN-MUI Pusat mengenai produk akad bagi pelaksanaan praktik bisnis di bank syariah, di antaranya:

\section{Akad Penghimpunan Dana (Funding)}

Tabungan (Fatwa DSN-MUI No. 02/DSN-MUI/IV/2000). Perbedaan esensial antara tabungan di bank syariah dan tabungan di bank konvensional, bahwa tabungan di bank syaraiah berdasarkan prinsip mudharabah dan wadi'ah, ${ }^{32}$ sedangkan di bank konvensiaonal tabungan berdasrkan prinsip bunga semata. Alih-alih mendaptkan bunga, malah biaya administrasi yang besar yang dibebakan kepada nasabah rata-rata simpanan kurang dari 10 juta menjadi nihil dari bunga. Prinsip mudharabah adalah bagi hasil antara bank dengan nasabah dimana nasabah sebagai shahibul mal (pemilik dana), adapun bank sebagai mudharib (yang mengoperasikan bisnis). Jlka tabungan berakad wadi'ah (titipan), bank tidak memperjanjikan hasil bagi nasabah, melainkan mendapatkan bonus yang tidak diperjanjikan dari awal besarannya baik nisbah ataupun nilainya.

Deposito (Fatwa DSN-MUI No. 03/DSN-MUI/IV/2000). Perbedaan esensial antara deposito di bank syariah dan deposito di bank konvensional, bahwa deposito di bank syariah berprinsip mudharabah (bagi hasil) yang berorientasi kepada nisbah, bukan kepada pokok simpanannya, sehingga hasilnya tidak tetap bergantung kepada hasil usaha bank. Adapun deposito di bank konvensional berprinsip bunga yang berorientasi pada prosentasi pokok simpanan.

\section{Akad Pembiayaan (ekspansing)}

Pembiayaan Mudharabah (Qiradh) (Fatwa DSN-MUI No. 07/DSN-MUI/IV/2000). Dalam hal ini Bank berkedudukan sebagai shahibul mal (pemilik dana) sedangkan nasabah berkedudukan sebagai mudharib (yang mengoperasikan bisnis) berprinsip bagi hasil yang berorientasi kepada nisbah.

Pembiayaan Murabahah (Fatwa DSN-MUI No:04/ DSN-MUI/ IV/2000). Murabahah yang dimaksud adalah menjual suatu barang dengan menegaskan harga belinya kepada pembeli dan pembeli membayarnya dengan harga yang lebih sebagai laba. Berbeda dengan bank yang ada di Timur Tengah, umpamanya di Qatar, spesipikasi barang yang diperjualbelikan langsung disediakan oleh pihak bank murni sebagai penjual, sedangkan di Indonesia pada umumnya bank tidak melakukan pengadaan barang, tetapi melalui akad wakalah dengan penyerahan uang kepada nasabah untuk mencari spesipikasi barang yang diinginkan.

Pembiayaan Musyarakah (Fatwa DSN-MUI No: 73/DSN-MUI/XI/2008). Musyarakah yang dimaksud merupakan skema kerjasama antara pihak bank syariah dan nasabah dalam hal penambahan modal kerja. Perbedaan mendasar dengan skema mudharabah

${ }^{32}$ Ichwan Syam dkk. Himpunan Fatwa Dewan Syariah Nasional MUI, Dewan Syariah Nasional MUIBank Indonesia, Jakarta: 2006, hlm. 12. 
dalam skema musyarakah nasabah telah mempunyai modal usahanya, sedangkan pada mudharabah nasabah hanya sebagai orang yang mengoperasikan dana titipan dari pihak bank sebagai shahibul mal (pemilik dana).

Pembiayaan ljarah (Fatwa DSN No: 09/ DSN-MUI/ IV/ 2000). Pada pembiayaan ini lazimnya pihak nasabah memerlukan jasa atau barang dari pihak lain dalam menunaikan keperluannya melalui pihak bank pembayaran dilakukan dengan mengenakan ujrah (jasa).

Pembiayaan Al-ljarah Al-Muntahiya Bi Al-Tamlik (Fatwa DSN No: 27/ DSN-MUI/ III/ 2002). Akad ini tergolong unik karena merupakan produk asli "Fiqh Indonesia" yang lebih dikenal dalam keseharian dengan nama akad "sewa beli", yaitu perjanjian sewamenyewa yang diakhiri dengan opsi pemindahan hak milik atas benda yang disewa, kepada penyewa, setelah selesai masa sewa.

Pembiayaan Istishna' (Fatwa DSN No: 06/ DSN-MUI/VI/ 2000). Pembiayaan ini pada esensinya jual beli dalam bentuk order pembuatan barang tertentu dengan kriteria dan persyaratan tertentu yang disepakati antara pemesan (pembeli, mustashni') dan penjual (pembuat, shani). Lazimnya pada praktik akad ini berhubungan dengan pembiayaan terhadap suatu proyek yang dikerjakan umpamanya oleh seorang developer.

Pembiayaan Rahn (Fatwa DSN No: 25/ DSN-MUI/ III/ 2002). Pembiayaan Rahn adalah pinjaman dengan menggadaikan barang sebagai koleteral atas utang. Yang menarik dari akad ini seharusnya menjadi akad ta'awun, tetapi karena volume yang meningkat pesat pernah menjadi trend di bank syariah.

Signifikansi Penerapan Fatwa di Balik Pesimistis dan Antipati

Majelis Ulama Indonesia dengan DSN-MUI telah berupaya membumikan semangat Qurani yang terlibat secara langsung dengan regulasi dalam hal ini OJK untuk mengaplikasikan praktik akad-akad bermu'amalah dalam lingkup ekonomi Islam secara khusus dalam pembahasan makalah ini samplenya bank syariah. Aspek kondisionalitas dan fleksibilitas begitu kentara dalam item-item fatwanya membuat sebagian komunitas yang menghendaki kemurnian syariah, dan ditanggapi dengan pesimistis dan antipasti. Hijbut Tahrir Indonesia ( $\mathrm{HTI}$ ) umpamanya, mengkritik semua fatwa DSN-MUI sebagai akad yang tidak sah, karena semua akad mengandung dua akad. Akad murabahah (jual beli), umpamanya, masih dikenakan syarat koleteral. Dengan penyerahan koletaral berarti sama dengan terkandung akad gadai, disini difahami sebagai pemberlakuan dua akad yang tidak mencerminkan kemurnian dalam pandangan syaraiah. Walaupun ulama di kalangan HTI Indonesia menganggap batal semua fatwa DSN MUI ternyata semua rekening jalur donasi HTI Indonesia disimpan di bank syariah.

Beda halnya dengan golongan yang antipati terhadap bank syariah, mereka membuat suatu komunitas yang bernama LARIBA Indonesia. Kelompok yang terhimpun 
dari entitas para pengusaha Muslim yang sadar sepenuh hati bahaya riba ini, atau mungkin mereka pernah terjerumus sangat dalam ke dalam praktik ribawi yang merugikan, berusaha membangun rekanan bisnis dengan entitasnya dalam penghimpunan capital dan penyalurannya yang mengandalkan "saling percaya" dalam share dana ataupun barang. Sangat disayangkan dari golongan ini berpikir jauh mundur dari kemodernan dunia keuangan. Mungkin belum seratus persen praktik akad perbankan syariah itu dalam pelaksanaannya, tetapi menurut hemat penulis bukan harus ditinggalkan secara keseluruhan, karena jika ditinggalkan secara keseluruhan tentunya akan membesarkan bank konvensional yang jelas-jelas bergelimang dengan ribawinya. Dalam suatu rumusan qaidah fiqhiyah menyatakan:

$$
\text { ما لايدرك كله لايترك كله }
$$

"Sesuatu yang tidak dapat diraih seluruhnya tidak boleh ditinggalkan seluruhnya."

\section{Simpulan}

Kondisionalitas Al-Qur'an bermakna pengkondisian yang dituntut oleh 'illat alhukum (motif hukum) dalam kerangka tathbiq al-hukm (pengaplikasian hukum) yang dikehendaki oleh faktor keadaan, waktu, dan tempat sehingga hukum berubah dari 'azimah (asalnya) jika 'illatnya manshush 'alaih menjadi rukhshah, jika 'illatnya ghair manshus terhadap kasus baru bisa diterapkan qiyas (analogi).

Dimensi fleksibilitas Al-Qur'an menunjukkan bahwa eksistensi Al-Qur'an senantiasa luwes merespon tuntutan seukuran dengan tempat dan waktu yang melingkupinya tanpa mengabaikan tujuan syari'ah. Fleksibilitas Al-Qur'an merespon segala problema kehidupan manusia dari sigi syumuliyah-nya tidak terbatas pada teks-teks qath'i untuk menampung problema kehidupan guna mengantisifasi percepatan dinamika zaman. Bahkan dari teks-teks itu berkembang karena keumuman maknanya yang mencakup semua partikular (juz'iyah) di samping spirit ayat yang membuka pengamalan kontekstual.

Indonesia memiliki lembaga Majelis Ulama Indonesia (MUI) yang menunjuk unit kerjanya Dewan Syariah Nasional (DSN) MUI sebagai lembaga otoritas fatwa yang masuk ke dalam wilayah regulasi legislasi aplikasi akad syariah yang dipraktikkan oleh dunia perbankan di Indonesia. Bank syariah telah mendapatkan legislasi dari Bank Indonesia dan diterbitkan peraturan oleh Otoritas jasa Keuangan (OJK). Kehadiran institusi Fatwa DSN merupakan bukti implikasi dimensi kondisionalitas dan fleksibilitas ayat-ayat Al-Qur'an dalam bidang ekonomi syariah. 


\section{DAFTAR PUSTAKA}

Al-'Utsaimin, Muhamad bin Shalih, Syarh Riyadh Al-Shalihin, Beirut: Dar Ibn 'Ashashat, 2006.

Al-Alusi, Syihab Al-Din Mahmud bin Abdillah Al-Husaini. Ruh Al-Ma'ani, Beirut: Dar AlKutub Al-'Ilmiyat, 1415.

Al-Khudlari Bik, Al-Syaikh Muhamad. Ushul Al-Fiqh.Beirut: Dar Al-Fikr, 1988.

Al-Qasimi, Muhamad Jamal Al-Din bin Sa'id bin Qasim Al-Halaq. Mahasin Al-Ta'wil, Beirut: dar Al-Kutub Al-'Ilmiyat, $1418 \mathrm{H}$.

Al-Shabuni, Muhamad Ali, Al-Tibyan Fi 'Ulum Al-Qur'an, Dar Al-Mawahib Al-Islamiyat: 2016.

Al-Shalih, Shubhi. Mabahits Fi 'Ulum Al-Qur'an, Beirut: Dar Al-'Ilm Lil Malayin, 1988.

Al-Zhahiri. Abu Muhamad 'Ali bin Ahmad bin Sa'id bin Hazm Al-Andalusi Al-Qurthubi, AlMuhalla Bi Al-Atsar, Beirut: Dar Al-Kutub Al-'llmiyat, 2008.

Al-Zuhaili, Wahbah bin Mushtafa. Tafsir Al-Munir, Damaskus: Dar Al-Fikr, $1418 \mathrm{H}$.

Anonimous, Al-Qur'an Hafalan Mudah, Bandung: Cordoba, 2018.

Hakim, Abdul Hamid. Mabadi'u Awaliyat, Jakarta: Maktabat Al-Sa'adiyat Putra, 2007.

https://kkbi.web.id/dimensi.html, diakses pada tanggal 18 Mei 2020

Ibn Katsir, Tafsir Al-Qur'an Al-'Azhim, Beirut: Dar Al-Fikr, 1992.

Nazir, Moh., Metode Penelitian, Bandung: Ghalia Indonesia, 2003.

Rahmat, Jalaludin. Metodologi Hukum. Jakarta: Fajar Agung, 1997.

Sugiyono, Metode Penelitian Kuantitatif, Kualitatif Dan R\&D, Bandung: Alfabeta, 2013.

Sukanto, Suerjono dan Mamudji, Sri. Penelitian Hukum Normatif Suatu Tinjauan Singkat, Cet. 11, Jakarta: PT. Raja Grafindo Persada, 2009.

Syam, Ichwan dkk. Himpunan Fatwa Dewan Syariah Nasional MUI, Jakarta: Dewan Syariah Nasional MUI-Bank Indonesia, 2006.

Thanthawi, Muhamad Sayyid. Al-Tafsir Al-Wasith Li Al-Qur'an Al-Karim, Kairo: Dar Nahdhat, 1997.

Wahbat Al-Zuhaili, Ushul Al-Fiqh Al-Islami, Damaskus: Dar Al-Fikr, 2006.

www.pengertianmenurutparaahli.net, diakses pada tanggal 18 Mei 2020. 
66 | Asy-Syari'ah Vol. 22 No.1, Juni 2020 
Asy-Syari'ah (P-ISSN: 2086-9029 E-ISSN: 2654-5675) is a periodical scientific journal that publishes various results of studies and research, literature review, and other scientific works whose scope covers the field of Islamic law/sharia, law and society in monodisciplinary, interdisciplinary, and multidisciplinary manners. The journal aims to expand and create innovative concepts, theories, paradigms, perspectives and methodologies in the above said scope. The Journal is published twice a year (june and december) by Faculty of Shariah and Law, Sunan Gunung Djati State Islamic University Bandung in collaboration with Asosiasi Sarjana Syariah Indonesia (ASSYI).

\section{EDITORIAL OFFICE:}

Fakultas Syariah dan Hukum UIN Sunan Gunung Djati Bandung J1. Raya A.H. Nasution No. 105 Cibiru Kota Bandung, 40614

Tlp/Fax: +022-7802278 Faks. 022-7802278

Website http://journal.uinsgd.ac.id/index.php/asy-syariah/index

E-mail: Jurnalasy-syariah@uinsgd.ac.id 
p-ISSN. 2086-9029

e-ISSN. 2654-5675

Vol. 22 No. 1, Hlm. 1-158, Juni 2020

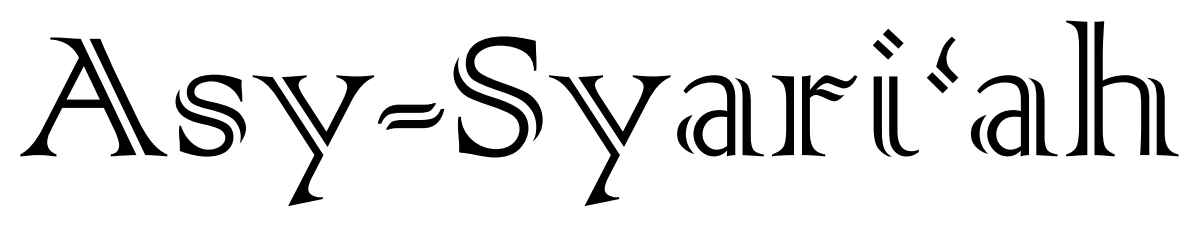

- Hukum Waris Islam Sebagai Instrumen Kepemilikan Harta

$(1-20)$ Hafidz Taqiyyudin

- Komparasi Metodologi Hukum Aliran Maqasidi dan Aliran Syakli

$(21-34)$ Hudzaifah Achmad Qotadah

- Reinterpretasi Hak Ijbar dalam Hukum Perkawinan Islam di Keluarga $(35-50)$ Pesantren

Kudrat Abdillah

- Dimensi Kondisionalitas dan Fleksibilitas Al-Quran bagi Implementasi $(51-66)$ Fatwa DSN-MUI tentang Produk Bank Syariah

Ahmad Hasan Ridwan, Asep Rahmat

- Validitas Hadis Tidak Ada Kisas bagi Orang Tua yang Membunuh Anaknya

Moh. Ahsanuddin Jauhari, Enceng Arif Faizal, Syahrul Anwar, Atep Mastur, Deden Najmudin

- Penguatan Resolusi Konflik Berbasis Tradisi Sunnah Nabi

Alamsyah

- Sistem Perencanaan, Pelaksanaan dan Pengawasan Industri Halal di Wilayah Provinsi Banten

Akhyakudin, Suja'i, Muhammad Abduh

- Reformulation of Family Legal in Indonesia for Female Maslahah

Wahidullah, Murniati, Yushinta Eka Farida, Jumaiyah

- The Concept and Aplication of Covenant in Financing Gold Pawn By Sharia Bank in West Java

Neni Nuraeni, Dewi Sulastri, Zulbaidah

- Tinjauan Sosiologi Hukum tentang Kepatuhan Masyarakat terhadap ( $147-158)$ Undang-Undang Wakaf

Deden Effendi

FACULTY OF SHARIA AND LAW

STATE ISLAMIC UNIVERSITY SUNAN GUNUNG DJATI BANDUNG-INDONESIA IN COLLABORATION WITH ASOSIASI SARJANA SYARIAH INDONESIA 


\section{Asy-Syari'ah}

Volume 22, Number 1, 2020

\section{EDITOR-IN-CHIEF}

Ine Fauzia

\section{EDITORIAL BOARD}

Sofyan al-Hakim, UIN Sunan Gunung Djati Bandung, Indonesia Deni Kamaludin Yusup, UIN Sunan Gunung Djati Bandung, Indonesia Meria Utama, Fakultas Hukum Univrsitas Sriwijaya, Indonesia Dewi Mayaningsih, UIN Sunan Gunung Djati Bandung, Indonesia Andrey Sujatmiko, Fakultas Hukum Universitas Trisakti, Jakarta, Indonesia Hetty Hassanah, Universitas Komputer Indonesia, Indonesia

\section{PEER-REVIEWERS}

Muhammad Irfan Helmy, IAIN Salatiga, Semarang, Indonesia Ahmad Ali Nurdin, UIN Sunan Gunung Djati Bandung Tajul Arifin, UIN Sunan Gunun Djati Bandung, Indonesia Mohamad Anton Athoillah, UIN Sunan Gunung Djati Bandung, Indonesia Mrs. Renny Supriyatni, Universitas Padjadjaran, Indonesia Ahmad Tholabi Karlie, UIN Syarif Hidayatullah Jakarta, Indonesia Ija Suntana, UIN Sunan Gunung Djati Bandung, Indonesia Zezen Zaenal Mutaqin, University of California, Los Angeles, United States Ahmad Fathonih, UIN Sunan Gunung Djati Bandung, Indonesia Rahman Syamsuddin, Universitas Islam Negeri Alauddin Makassar, Indonesia

\section{PROOFREADER/DESIGN COVER}

Nanang Sungkawa

\section{LAYOUT EDITOR}

Opik Rozikin

Asy-Syari' ah has been accredited based on the determination of Director General of Research and Development Strengthening, Ministry of Research, Technology and Higher Education of Republic of Indonesia, No. 14/E/KPT/2019 (valid until 2023). 